\title{
Infiltration Characteristics and Spatiotemporal Distribution of Soil Moisture in Layered Soil under Vertical Tube Irrigation
}

\author{
Cheng Wang ${ }^{1}$, Dan Bai ${ }^{1}{ }^{*}$, Yibo Li ${ }^{1}$, Xinduan Wang ${ }^{2}$, Zhen Pei ${ }^{1}$ and Zuochao Dong ${ }^{1}$ \\ 1 State Key Laboratory of Eco-hydraulics in Northwest Arid Region, Xi'an University of Technology, \\ Xi'an 710048, China; chengw8973@163.com (C.W.); liyibo51_teresa@hotmail.com (Y.L.); \\ p18829029376@163.com (Z.P.); dongzuochao2020@163.com (Z.D.) \\ 2 School of Science, Xi'an Polytechnic University, Xi'an 710048, China; wxdcdyan@163.com \\ * Correspondence: baidan@xaut.edu.cn; Tel.: +86-029-8231-2780
}

Received: 31 July 2020; Accepted: 25 September 2020; Published: 29 September 2020

\begin{abstract}
The limited quantity of irrigation water in Xinjiang has hindered agricultural development in the region and water-saving irrigation technologies are crucial to addressing this water shortage. Vertical tube irrigation, a type of subsurface irrigation, is a new water-efficient technology. In this study, field and laboratory experiments were conducted to analyze (1) the infiltration characteristics and spatiotemporal distribution of moisture in layered soil and (2) the water-saving mechanism of vertical tube irrigation. In the field experiments, we analyzed jujube yield, irrigation water productivity (IWP), and soil moisture in the jujube root zone. In the laboratory irrigation experiments, two soil types (silty and sandy loam) were selected to investigate homogeneous and layered soil, respectively. Cumulative infiltration, wetting body, and soil water moisture distribution were also analyzed. Relative to surface drip irrigation, vertical tube irrigation resulted in slightly lower jujube yields but higher savings in water use (47-68\%) and improved IWP. The laboratory experiments demonstrated that layered soil had less cumulative infiltration, a larger ellipsoid wetted body, slower vertical wetting front migration (hindered by layer interface), and faster horizontal wetting front migration than homogenous soil had. The irrigation amount for vertical tube irrigation decreased in layered soil, and water content increased at the layer interface. Vertical tube irrigation in layered soil facilitates the retention of water in the root zone, prevents deep leakage, reduces irrigation amount, and improves the IWP of jujube trees. This study aids the popularization and application of vertical tube irrigation technology.
\end{abstract}

Keywords: vertical tube irrigation; layered soil; soil moisture distribution; water-saving irrigation

\section{Introduction}

Water shortages constitute the main factor restricting agricultural development in arid and semiarid areas. Water-efficient irrigation technology is a key means of promoting agricultural development. Subsurface irrigation can effectively save irrigation water by directly transporting water and fertilizer to the rhizosphere through irrigation emitters buried in the soil. Furthermore, it can reduce the irrigation amount and the amount of evaporation, and improve crop yield and water use efficiency [1-6]. Subsurface irrigation technologies include many types, such as subsurface drip irrigation [7-9], porous ceramic irrigation [10], and trace quantity irrigation [11]. Although these technologies are widely used in agriculture, their wide-scale application is constrained by complex manufacturing processes, high working head, and emitter plugging [12,13]. Many experiments and numerical simulations of water flow into soil, the wetting body, soil moisture distribution, and influencing factors of irrigation techniques have been performed [14-17]. 
Vertical tube irrigation is a new subsurface irrigation technology in which the emitter, a tube with a diameter of 10-20 mm [18], is vertically embedded in the soil. The upper end of the emitter is connected to a water supply pipe, and the lower end of the emitter is open and tightly connected to the soil. Generally, the working head is less than $1 \mathrm{~m}$. Vertical tube irrigation can continually supply water to the plant throughout the irrigation cycle. Bai et al. $[18,19]$ reported the influence of various factors on irrigation discharge, on the spatiotemporal distribution of soil moisture, and on the infiltration process in homogeneous soil. These factors include the working head, vertical tube diameter, physical properties of the soil, and depth of the outlet of the vertical tube emitter.

The total planted area of jujube trees in China accounts for more than $50 \%$ of the global total, and China is the primary jujube exporter. Jujube is mainly cultivated in southern Xinjiang, and scientifically designed irrigation is required for high yield. Given the extreme water shortage in southern Xinjiang, we aimed to apply vertical tube irrigation to jujube cultivation to reduce the amount of irrigation water used. The effects of irrigation are closely related to the soil. Furthermore, the complex structure of soil, especially layered soil, affects the distribution of moisture and the growth of crops. Many laboratory and field infiltration experiments have been performed to uncover the rules governing water movement in layered soil $[20,21]$. The texture and thickness of layered soil affect infiltration characteristics, and the wetting front may stagnate at the layer interface. The wetting front cannot enter the next layer until the soil water moisture of the upper layer is saturated, especially when hydraulic conductivity of the lower layer is greater than that of the upper layer. Hence, layer interfaces may hinder the infiltration process [22,23]. Water movement in layered soil is not a continuous process [24,25]; when the soil matric potential of the lower layer of soil is greater than that of the upper layer, the water enters the lower layer of soil through the layer interface [22].

The water infiltration of vertical tube irrigation in soil is three-dimensional, and it is more complex than simple one-dimensional infiltration. Li et al. [26] used simulations to analyze the soil water movement of subsurface drip irrigation emitters in layered soil, but the problem of water resistance caused by layer interfaces has not been solved. Therefore, we performed field and laboratory infiltration experiments on vertical tube irrigation to study the spatiotemporal distribution of soil moisture in layered soil. Our findings provide a basis for the future design and management of vertical tube irrigation systems in layered soil. Our research aims are: (1) To determine the effects of vertical tube irrigation on jujube yield and IWP of jujube tree; (2) to analyze the spatiotemporal distribution characteristics of soil moisture with vertical tube irrigation in layered soil; and (3) to analyze the water saving mechanism underlying vertical tube irrigation in layered soil.

\section{Materials and Methods}

Both field and laboratory experiments were performed using subsurface vertical tube irrigation. In the first set of field experiments, we measured the infiltration and soil moisture distribution of the jujube root zone. The second set of experiments was performed in a laboratory.

\subsection{Field Experiments}

Field experiments of vertical tube irrigation were performed at the jujube experimental base $\left(80^{\circ} 50^{\prime} \mathrm{E}, 40^{\circ} 29^{\prime} \mathrm{N}\right)$ in Alear, Xinjiang, China (Figure 1). The experimental object was a 6-year-old jujube planted in a plot with a width of $2.5 \mathrm{~m}$ and a length of $3.0 \mathrm{~m}$ (Figure 2). The soil profile exhibited a clear stratified structure. Soil at the layer depth of $0-50 \mathrm{~cm}$ was silty loam, and that at $50-200 \mathrm{~cm}$ was sandy loam. Soil bulk density and the initial water content of upper and lower soil layers were measured by drying soil samples in an oven. Soil samples were collected from the field plot and loaded into a steel ring (volume is $100 \mathrm{~cm}^{3}$, height is $5.0 \mathrm{~cm}$ ). All soil samples were soaked for $24 \mathrm{~h}$ to measure saturated water content. The physical properties of the soil samples are presented in Table 1. 


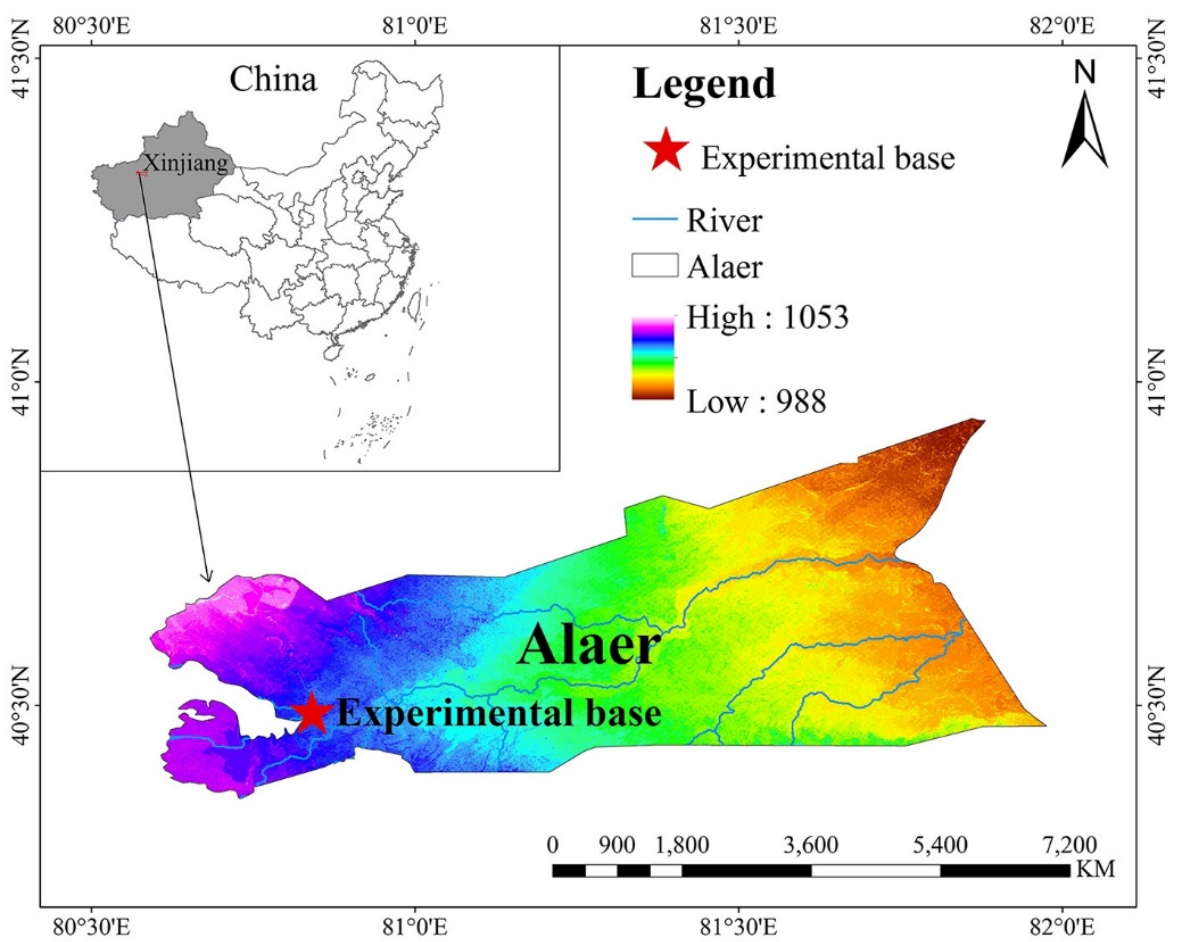

Figure 1. Location of the experimental base.
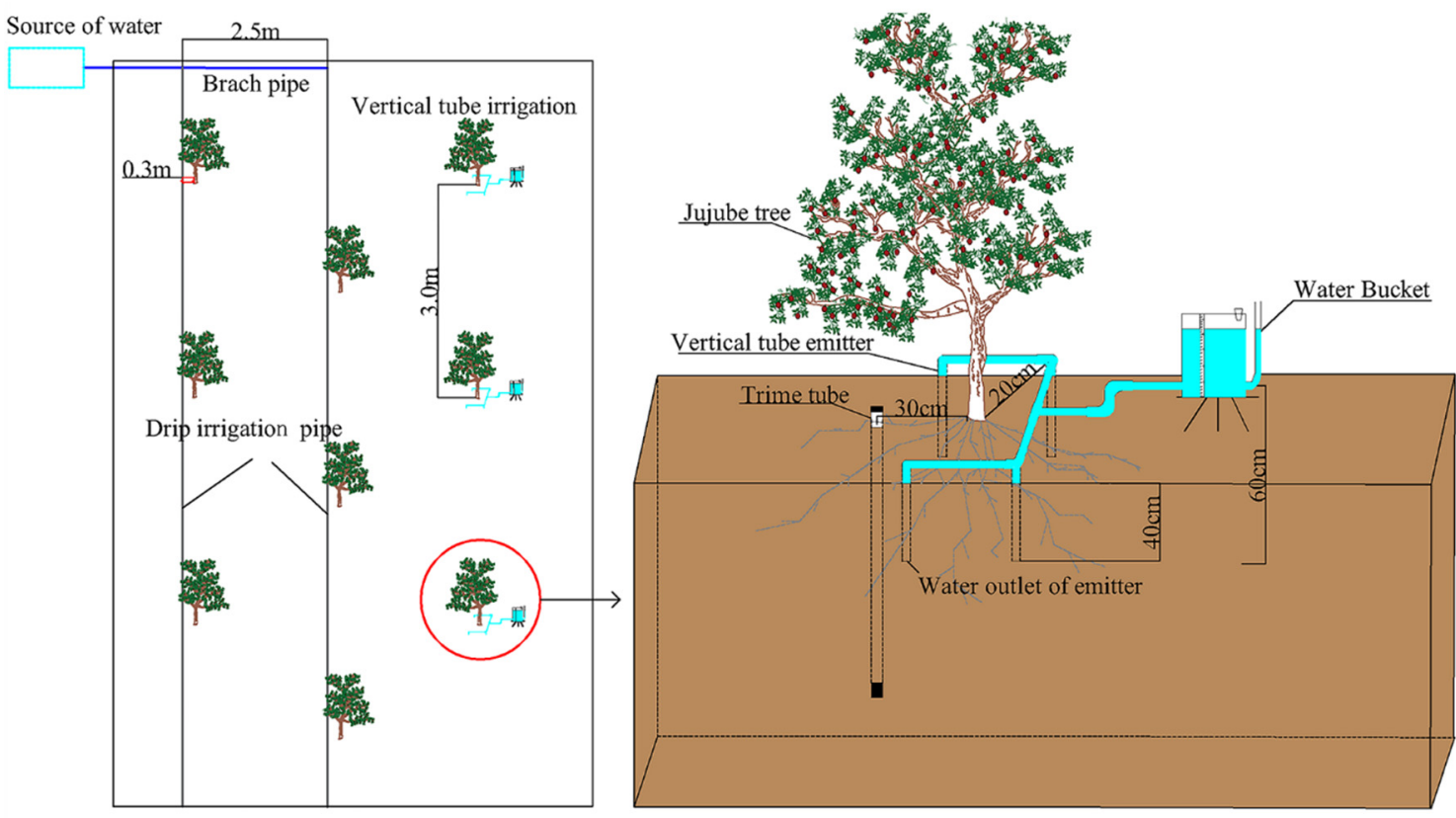

Figure 2. The field experiment setup for vertical tube irrigation and drip irrigation.

The test field was $27 \mathrm{~m}$ in length and $20 \mathrm{~m}$ in width. Three jujube trees were selected for vertical tube irrigation, and the remaining trees received surface drip irrigation. Spring irrigation was conducted on 15 March 15 2017, with an irrigation amount of $31.03 \mathrm{~mm}$. Spring irrigation is a flood irrigation technique that is usually applied to saline-alkali areas every spring. It can desalinize the soil in root zone and leach the salt accumulated through saline water irrigation. Vertical tube irrigation (11 June-24 July 2017) was performed during the jujube blossom and young fruit period and the developing fruit period. The height difference between the air inlet of the water supply equipment 
(cuboid water bucket made from the principle of Markov bottle, length $\times$ width $\times$ height: $29.6 \mathrm{~cm} \times$ $24.6 \mathrm{~cm} \times 35 \mathrm{~cm}$ ), and the water outlet of the vertical tube was at $0.6 \mathrm{~m}$ (pressure head). The vertical tube emitter (made of polyvinyl chloride) had a length of $450 \mathrm{~mm}$ and an inner diameter of $16 \mathrm{~mm}$. The upper end of the vertical tube emitter was connected to a water supply pipe, and the lower end outlets were buried $40 \mathrm{~cm}$ below the soil surface. Each tree had four vertical tube emitters $(20 \mathrm{~cm}$ away from the jujube) to supply water (Figure 2). Each treatment was regarded as one experimental plot (each treatment had one jujube), and each treatment was repeated three times. Surface drip irrigation was applied to the other jujube trees by using one lateral pipe parallel to the row of trees $(30 \mathrm{~cm}$ from the jujube trees). Drip emitter spacing was $20 \mathrm{~cm}$, and the discharge was $4 \mathrm{~L} \cdot \mathrm{h}^{-1}$. Each tree was irrigated three times (on 11 June, 23 June, and 24 July), for $12 \mathrm{~h}$ each time. Water meters were installed at the front end of each capillary, and used to record the irrigation amount for drip irrigation.

Table 1. Physical properties of soil layers used in this experiment.

\begin{tabular}{|c|c|c|c|c|c|c|c|}
\hline & \multicolumn{3}{|c|}{ Content/\% } & \multirow[b]{2}{*}{ Soil Texture ${ }^{b}$} & \multirow[b]{2}{*}{$\rho / \mathrm{g} \cdot \mathrm{cm}^{-3}$} & \multirow[b]{2}{*}{$\theta_{i} / \mathrm{cm}^{3} \cdot \mathrm{cm}^{-3}$} & \multirow[b]{2}{*}{$\theta_{s} / \mathrm{cm}^{3} \cdot \mathrm{cm}^{-3}$} \\
\hline & $\begin{array}{c}\text { Clay } \\
<0.002 \text { a }\end{array}$ & $\begin{array}{c}\text { Silt } \\
0.002-0.2\end{array}$ & $\begin{array}{l}\text { Sand } \\
2-0.2\end{array}$ & & & & \\
\hline \multirow{2}{*}{ Field } & 6.64 & 47.71 & 45.64 & Silty loam & 1.44 & 0.223 & 0.446 \\
\hline & 3.95 & 28.5 & 67.55 & Sandy loam & 1.47 & 0.221 & 0.437 \\
\hline \multirow{2}{*}{ Laboratory } & 6.78 & 47.01 & 46.21 & Silty loam & 1.44 & 0.098 & 0.419 \\
\hline & 5.57 & 30.85 & 63.58 & Sandy loam & 1.47 & 0.047 & 0.367 \\
\hline
\end{tabular}

a Particle diameter. $\rho$ : soil bulk density; $\theta_{i}$ : initial water content; $\theta_{s}$ saturated water content. ${ }^{\mathrm{b}}$ Classified according to the international system.

To measure the soil moisture distribution, a TRIME tube was installed $1.5 \mathrm{~m}$ deep, and $0.3 \mathrm{~m}$ away from the tree. The soil profile was measured at $20 \mathrm{~cm}$ intervals over the $100-\mathrm{cm}$-deep soil layer. The soil moisture content was measured at 9:00 a.m. every morning during the whole field experiment. The fruit yield of each jujube was calculated by weight.

\subsection{Laboratory Experiments}

To further uncover the influence of soil layering on the infiltration and water saving mechanism of vertical tube irrigation when applied to jujube tree, laboratory experiments were performed at the State Key Laboratory of Eco-hydraulics in Northwest Arid Region, Xi'an University of Technology, on November 2018. Experimental soil samples were collected from Xi'an's Loess Plateau. Soil textures were tested using a laser particle size analyzer (MS 2000, Malvern, England, United Kingdom), according to the international soil classification standard (Table 1). The basic physical properties of the experimental soils are displayed in Table 1.

The van Genuchten model [27] was used to generate soil water retention curves:

$$
\theta(h)=\left\{\begin{array}{cc}
\theta_{r}+\frac{\theta_{s}-\theta_{r}}{\left(1+|\alpha h|^{n}\right)^{m}} & h<0 \\
\theta_{s} & h \geq 0
\end{array}\right.
$$

where, $\theta(h)$ is the soil water content $\left(\mathrm{cm}^{3} \mathrm{~cm}^{-3}\right)$, $\mathrm{h}$ is the pressure head $(\mathrm{cm}), \theta_{r}$ is the residual water content $\left(\mathrm{cm}^{3} \cdot \mathrm{cm}^{-3}\right), \theta_{s}$ is the saturated water content $\left(\mathrm{cm}^{3} \mathrm{~cm}^{-3}\right), m, n$, and $\alpha$ are empirically fitted parameters, and $m=1-1 / n$.

RETC [28] is a software package for analyzing the relationship between soil water content and matric potential reflections, formulated by van Genuchten in 1980. RETC has the advantages of being able to quantify soil water retention and use hydraulic conductivity functions. Based on the data $\left(\theta_{s}, \rho\right.$, and soil particle diameter content) in Table 1, parameters in the van Genuchten model were fitted using RETC and are listed in Table 2. 
Table 2. Parameters of van Genuchten model for considered soil.

\begin{tabular}{cccccc}
\hline Soil Texture & $\boldsymbol{\theta}_{\boldsymbol{r}} / \mathbf{c m}^{3} \cdot \mathbf{c m}^{-3}$ & $\boldsymbol{\alpha} / \mathbf{m}^{-1}$ & $\boldsymbol{n}$ & $\boldsymbol{m}$ & $\boldsymbol{K}_{\boldsymbol{s}} / \mathbf{c m} \cdot \mathbf{m i n}^{\mathbf{- 1}}$ \\
\hline Silty loam & 0.0357 & 0.0129 & 1.4874 & 0.3277 & 0.0234 \\
Sandy loam & 0.0476 & 0.0359 & 3.4067 & 0.7065 & 0.5356
\end{tabular}

$\theta_{r}$ : residual soil water; $m, n$, and $\alpha$ : empirically fitted parameters, $m=1-1 / n ; K_{s}$ : hydraulic conductivity properties.

The experimental setup mainly consisted of four parts: the vertical tube emitter, soil box, water supply device, and soil moisture measurement system, as illustrated in Figure 3. The vertical tube emitter (made of polyvinyl chloride) had a length of $330 \mathrm{~mm}$ and an inner diameter of $12 \mathrm{~mm}$. The laboratory infiltration experiment was performed in a transparent soil container (made of polymethyl methacrylate), where one-fourth of the container was cylindrical in shape with a height of $50 \mathrm{~cm}$ and a bottom radius of $20 \mathrm{~cm}$ (net dimensions). The soil container was $0.2 \mathrm{~cm}$ thick. The two-side wall plate of the soil container had circular holes with apertures of $1.0 \mathrm{~cm}$ (diameter), and the distance between the centers of the holes was $5.0 \mathrm{~cm}$. The upper end of the vertical tube emitter was connected to a Markov bottle (5.0 $\mathrm{cm}$ in diameter) by a rubber tube, and the lower end was buried in the soil. Four soil moisture sensor probes (EC-5, Decagon Devices Inc., Pullman, WA, USA) were installed in the soil at different locations near the vertical tube emitter. The intersection of the edge of the one-fourth cylindrical soil container with the surface soil was taken as the origin $(0,0)$. With the surface soil as the reference plane, the positive $\mathrm{z}$ direction pointed downward and the positive $\mathrm{x}$ direction pointed to the right. The transverse and vertical coordinates of the soil moisture sensor probes of $(5,20),(0,18)$, $(4,25)$, and $(3,27)$, were denoted as A, B, C, and D, respectively. In the layered soil test, A, B, and C were buried in silty loam, whereas $\mathrm{D}$ was buried in sandy loam. The soil water content was measured and recorded at a time interval of $1 \mathrm{~min}$. The experimental setup is detailed in Table 3.

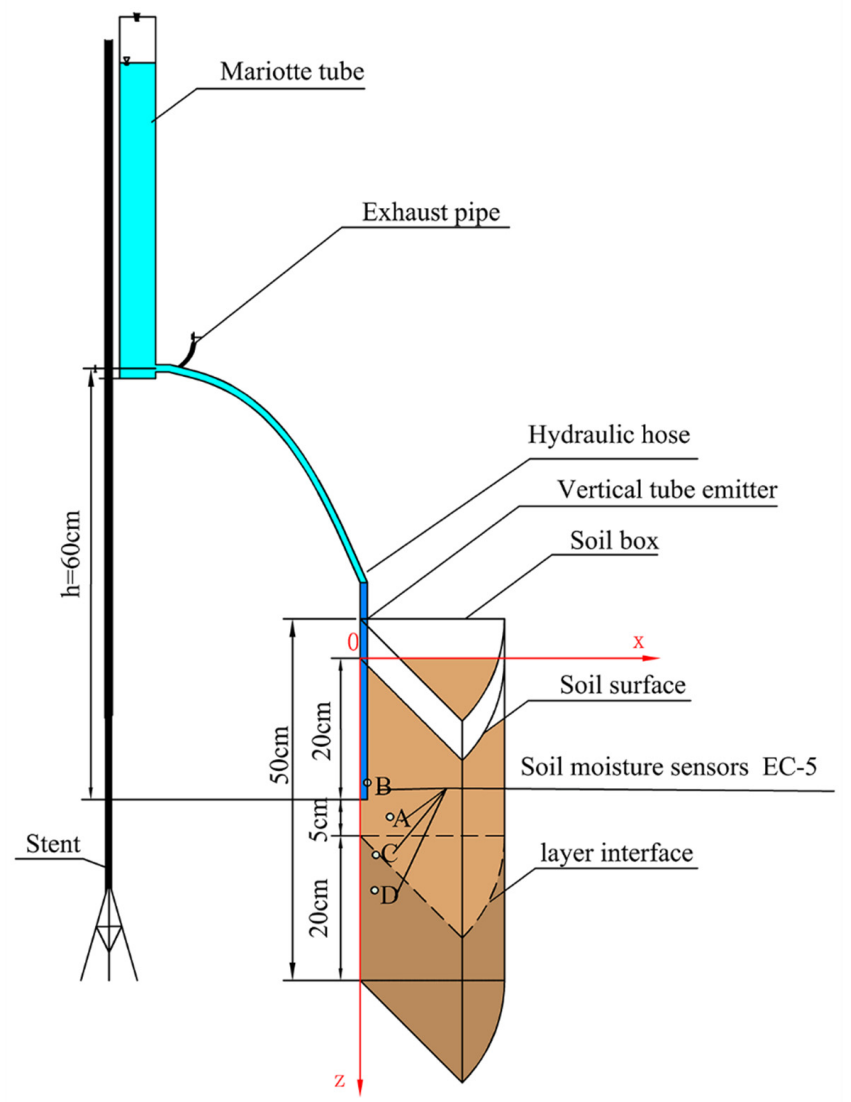

Figure 3. Laboratory experimental setup and instrumentation. 
Table 3. Experimental soil stratification.

\begin{tabular}{ccc}
\hline Depth/cm & Homogeneous Soil & Layered Soil \\
\hline $0-25$ & Silty loam & Silty loam \\
$25-45$ & & Sandy loam \\
\hline
\end{tabular}

Infiltration experiments on vertical tube irrigation were performed using homogeneous and layered soil. The specific test arrangements are displayed in Table 3. Soil samples were air dried and sieved through a 2-mm mesh. According to the scheme (Table 3) configuration, soil was compacted into $5 \mathrm{~cm}$ layers, which required close contact. Considering the connection between the pipe fittings and the continual supply of water, $\mathrm{h}_{0}$ was set as $0.6 \mathrm{~m}$ (the pressure head during the operation of the vertical tube irrigation emitter). The vertical tube was buried $20 \mathrm{~cm}$ below the surface (Figure 3).

The total infiltration time was $8 \mathrm{~h}$ for each treatment. During the first $10 \mathrm{~min}$, the recorded times were $0,1,3,5$, and $10 \mathrm{~min}$. Between 10 and $60 \mathrm{~min}$, the time interval was $10 \mathrm{~min}$ for every record. Between 1 and $3 \mathrm{~h}$, the time interval was $20 \mathrm{~min}$ for every record, and between 3 and $8 \mathrm{~h}$, the last interval was $1 \mathrm{~h}$. At different infiltration times, the water level in the Markov bottle was observed, and the wetting front was recorded. A cover film was applied to the soil surface to prevent evaporation. After infiltration, soil water content was measured using an oven drying method with soil samples taken from various depths of the soil (depths of 13, 16, 18, 20,25, 27, and $30 \mathrm{~cm}$ ). Infiltration tests of homogeneous soil and layered soil were repeated in groups of three, and the test values were the mean values of three tests.

\subsection{Irrigation Water Productivity}

Irrigation water productivity (IWP) [29] is defined as the ratio of irrigation water amount to crop yield. The IWP intuitively captures the effect on crop yields from the amount of irrigation water consumed, and it is thus a widely used indicator in agriculture for evaluating the effect of irrigation. IWP was calculated using the following equation:

$$
I W P=100 \frac{Y}{I}
$$

where IWP is expressed in $\mathrm{kg} \cdot \mathrm{m}^{-3}, Y$ is the jujube yield $\left(\mathrm{Mg} \mathrm{ha}^{-1}\right)$, and $I$ is the irrigation amount $(\mathrm{mm})$.

\section{Results}

\subsection{Field Experiment Results}

\subsubsection{Jujube Tree Yield and Water Productivity}

Jujube trees receiving vertical tube irrigation were irrigated continually for 44 days during the entire growth period. Surface drip irrigation was performed three times (according to the local irrigation system), for $12 \mathrm{~h}$ each time. Data on jujube yield $(Y)$, irrigation water amount $(I)$, and IWP for the experimental groups are presented in Table 4.

The two irrigation technologies significantly differed only with respect to amount of irrigation water $(p<0.05)$ and not in terms of yield or IWP. However, the IWP of vertical tube irrigation was 1.6 times that of surface drip irrigation. This may be due to the small discharge but continuous irrigation provided by vertical tube irrigation, in contrast to the cycle large-scale centralized that is characteristic of surface drip irrigation. The water from vertical tube irrigation can be stored in the buckets, whereas the water form surface drip irrigation falls into the soil and is thus more likely to be reduced by evaporation.

Second, vertical tube irrigation is type of subsurface irrigation, and the water is directly transported to the root layer; this improves the use of water by jujube trees. This was why vertical tube irrigation saved water while not compromising jujube yield, thereby improving IWP. 
Table 4. Jujube trees yield, irrigation water amount, and irrigation water productivity (IWP) under different treatments in the experimental years.

\begin{tabular}{ccccc}
\hline Irrigation Method & Experiments Number & $\mathbf{I} / \mathbf{m m}$ & $\boldsymbol{Y} / \mathbf{M g} \cdot \mathbf{h a} \mathbf{-}^{\mathbf{1}}$ & $\mathbf{I W P} / \mathbf{k g} \cdot \mathbf{m}^{-\mathbf{3}}$ \\
\hline \multirow{3}{*}{ Vertical tube irrigation } & 1 & 154 & 15.80 & 6.16 \\
& 2 & 254 & 14.36 & 3.39 \\
& 3 & 214 & 14.87 & 4.17 \\
Surface drip irrigation & $*$ & $207 \pm 41 \mathrm{~b}$ & $15.01 \pm 0.60$ & $4.57 \pm 0.12 \mathrm{a}$ \\
& 1 & 489 & 14.70 & 2.76 \\
& 2 & 483 & 15.10 & 3.02 \\
& 3 & 495 & 15.47 & 2.69 \\
& $*$ & $489 \pm 5 \mathrm{a}$ & $15.09 \pm 0.31$ & $2.82 \pm 0.14 \mathrm{~b}$ \\
\hline
\end{tabular}

*: Data are in terms of mean \pm SD standard deviation of three replicate samples; I: irrigation water amount; $Y$ : jujube yield; IWP: irrigation water productivity.

\subsubsection{Soil Moisture Distribution in the Field}

Beginning from $24 \mathrm{~h}$ after the first irrigation, soil moisture content was measured once per day (at 9:00 a.m.) until October 3 for a total of 115 days. The distribution of soil water content is illustrated in Figure 4. For vertical tube irrigation, soil moisture was $>26 \%$ at $0-50 \mathrm{~cm}$, and the moisture content at $50-100 \mathrm{~cm}$ gradually decreased from $24 \%$ (Figure $4 \mathrm{a}$ ). The outlet of the vertical tube emitter was buried $40 \mathrm{~cm}$ below the soil surface, and the water gradually diffused outward. As the soil water moisture of the outlet increases, the discharge of the vertical tube emitter decreases, and the water diffusion rate decreases. In particular, when water reaches the layer interface, the water potential of the upper soil was greater than the lower soil. Therefore, this may hinder the downward migration of water. Furthermore, surface soil moisture gradually evaporates, causing the moisture to migrate upwards, which explains why the soil moisture at the $0-50 \mathrm{~cm}$ root layer of silty loam is higher. The water-holding capacity of the upper soil is greater than the water-holding capacity of the lower soil, and less irrigation water enters the lower soil, which makes deep leakage unlikely to occur.

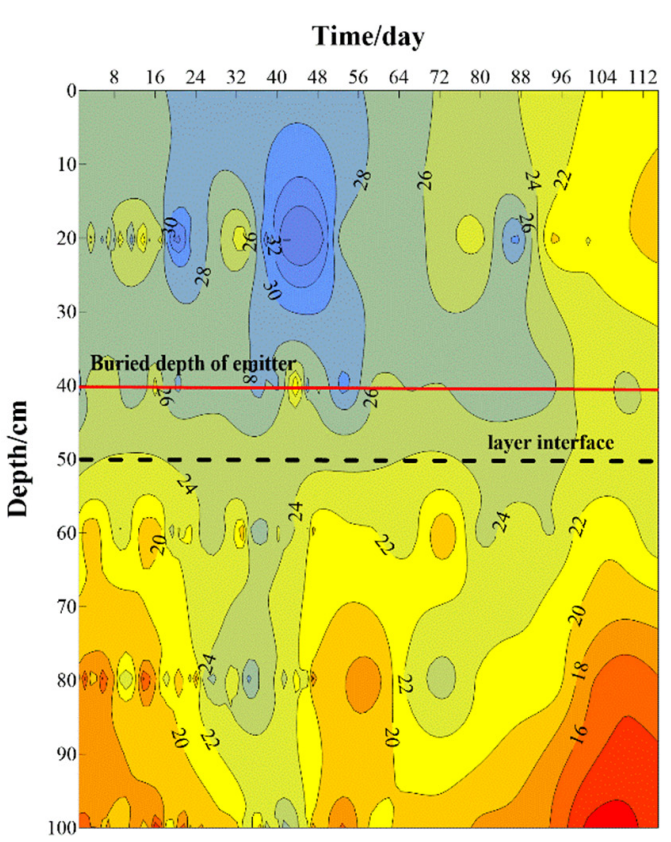

(a) vertical tube irrigation

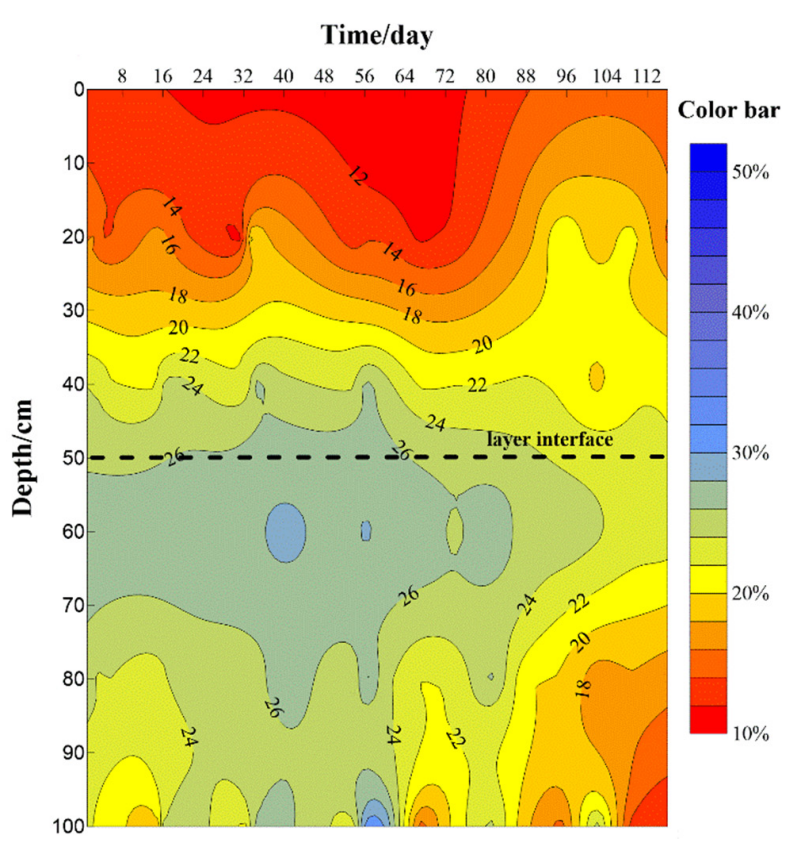

(b) surface drip irrigation

Figure 4. Vertical distribution of soil moisture content.

Because surface soil moisture is gradually reduced by evaporation, the upper layer $(0-50 \mathrm{~cm}$ depth from the surface) of the soil is relatively dry. Because of the poor water-holding capacity of 
sand, under the action of gravity, water can easily move downwards in the lower sandy soil to go even deeper. Most of the jujube roots were concentrated at the surface from 0-50 cm [30], whereas few were distributed in deeper soil. The soil moisture in the main jujube root distribution area can be maintained at a constant range through vertical tube irrigation. However, because all the water was irrigated at every single period during the surface drip irrigation, the large amount of irrigation water could move through the soil interface layer into deeper soil after irrigation, which was not conducive to the use of water by the main roots layer.

\subsection{Laboratory Experiment Results}

\subsubsection{Cumulative Infiltration}

Figure 5 illustrates the evolution of the cumulative infiltration for vertical tube irrigation. The infiltration process in layered soil can be divided into two stages [31]: (1) the infiltration of water above the layer interface, and (2) the infiltration of water through the layer interface to the lower soil. In the first stage, the infiltration process in homogeneous soil lasted for approximately $1 \mathrm{~h}$, and the wetting front moved to the position of the layer interface. Before the infiltration front reached the layer interface, the cumulative infiltration of layered soil and homogeneous soil were similar. In the second stage (at 1-8 h), the cumulative infiltration was lower in the layered soil than in the homogeneous soil. The cumulative infiltration amount in the homogeneous and layered soils were $198.63 \mathrm{~L}$ and 166.64 L, respectively. The cumulative infiltration in layered soil was $84 \%$ of that in homogeneous soil. The cumulative infiltration decreased when vertical tube irrigation in layered soil was used, a finding consistent with that of a previous study [32].

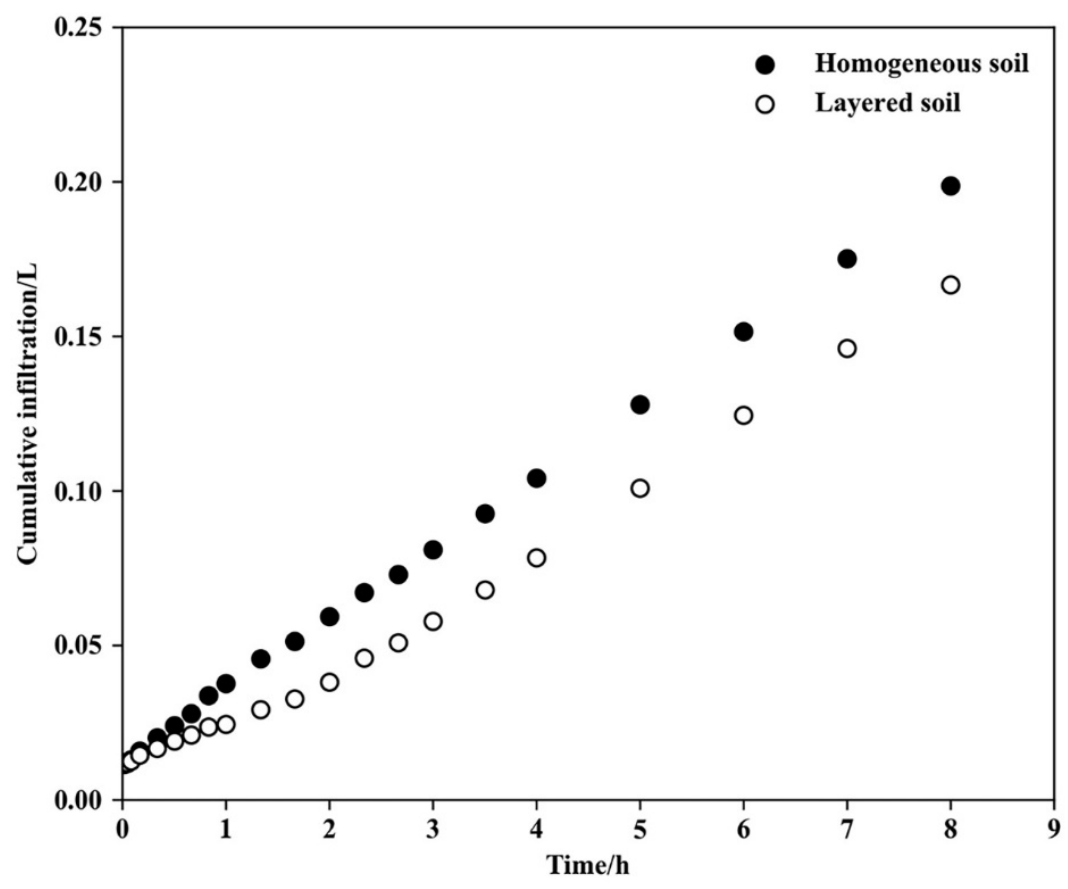

Figure 5. Evolution of cumulative infiltration.

\subsubsection{Wetted Body Changes with Time}

Figure 6 illustrates the variations in the wetted body over time. The vertical and transverse coordinates of the vertical tube emitter outlet were $(0,20)$, and 12 infiltration times $(1,5,20,40,60$, $120,180,240,300,360,420$, and $480 \mathrm{~min}$ ) were selected to draw the boundary line of the wetted body. Figure $6 \mathrm{a}, \mathrm{b}$ present variations in the wetted body over time in homogeneous and layered soil, respectively. The wetted body spread from the vertical tube emitter outlet, and the spread rate 
gradually decreased with infiltration time. Similar to that in homogeneous soil, the volume of the upper hemisphere of the wetting body was greater than that of the lower hemisphere. Because the lower layer was sandy soil with poor water-holding capacity and rapid water diffusion, the wetted body in layered soil was slightly larger than that in homogeneous soil.

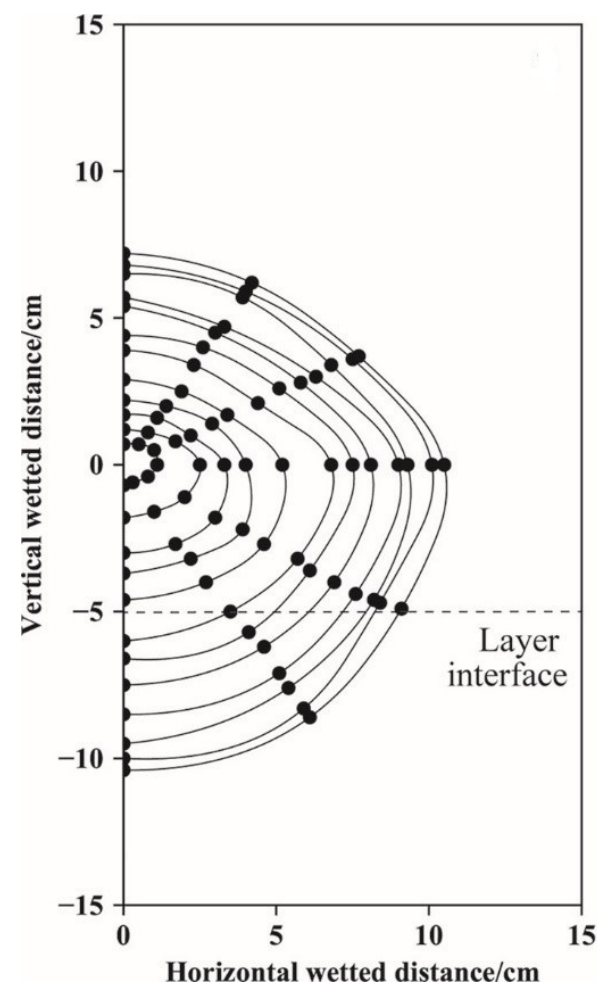

(a) Homogeneous soil

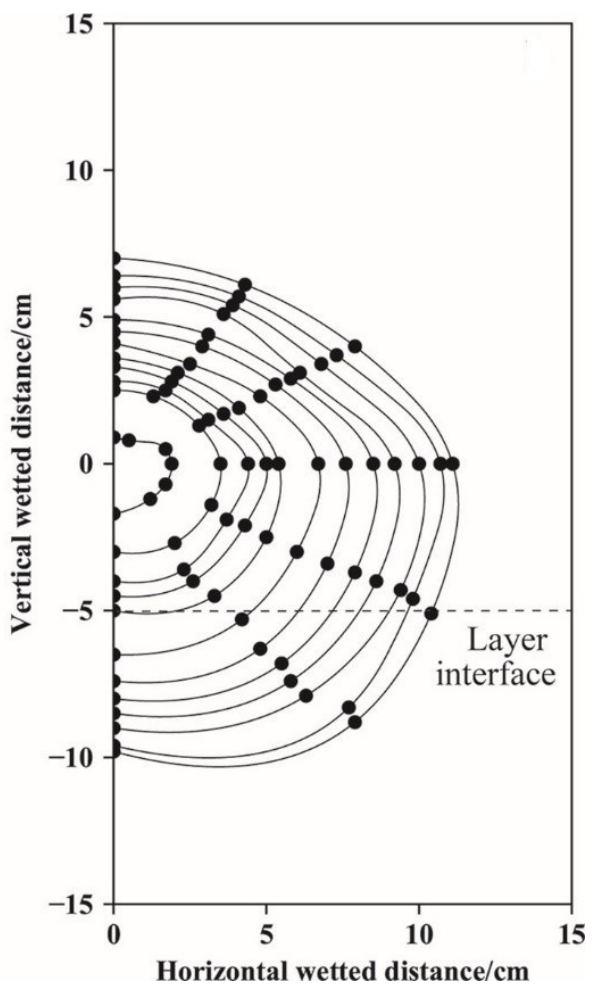

(b) Layered soil

Figure 6. Variations in wetted body with time. The boundary line of the wet body corresponds to 1,5, $20,40,60,120,180,240,300,360,420$, and $480 \mathrm{~min}$ from the inside to the outside.

Because the water-holding capacity of the upper soil was greater than that of the lower soil, the water potential difference at the layer interface affected the downward migration of moisture; under the influence of the soil matric potential, the moisture diffused horizontally. As soil moisture content increased, upper soil suction decreased gradually until it was equal to or less than the air intake suction of the lower sandy loam, and moisture moved downward through the layer interface. Because sandy soil has high water conductivity, any wetted body in sandy soil tends to diffuse rapidly. Therefore, the lower hemisphere body in layered soil was larger than that in homogeneous soil.

\subsubsection{Variation in Transport Distance of Wetting Front}

Figure 7 illustrates the variation in maximum wetting front transport distance over time in the upward, horizontal, and downward directions. After $8 \mathrm{~h}$ of infiltration, the upward migration distance was the smallest, and the difference between the horizontal and downward wetting front distances was nonsignificant. In the upward and horizontal direction, the maximum wetting front transport distance was determined by the soil texture. The transport distance of the downward wetting front in layered soil was not significantly different from that in homogeneous soil because the upper soil had a large water-holding capacity. Although less moisture entered the lower layer, the wetting front diffused quickly because of the high hydraulic conductivity of the sandy soil. 


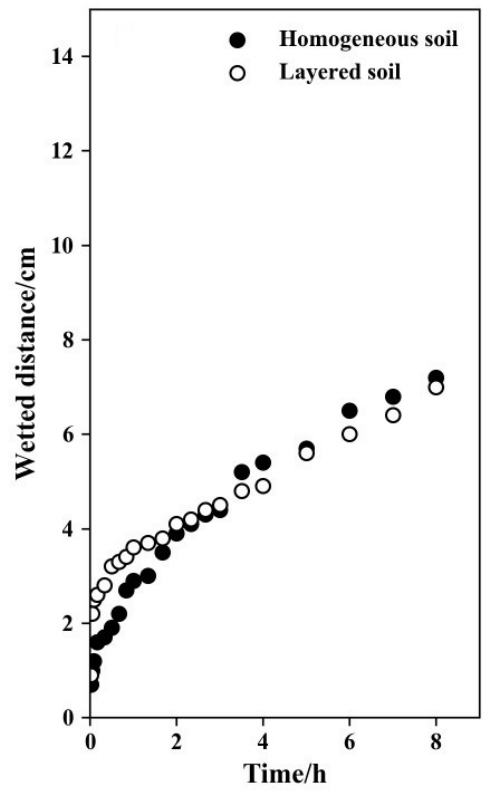

(a) Upward directions

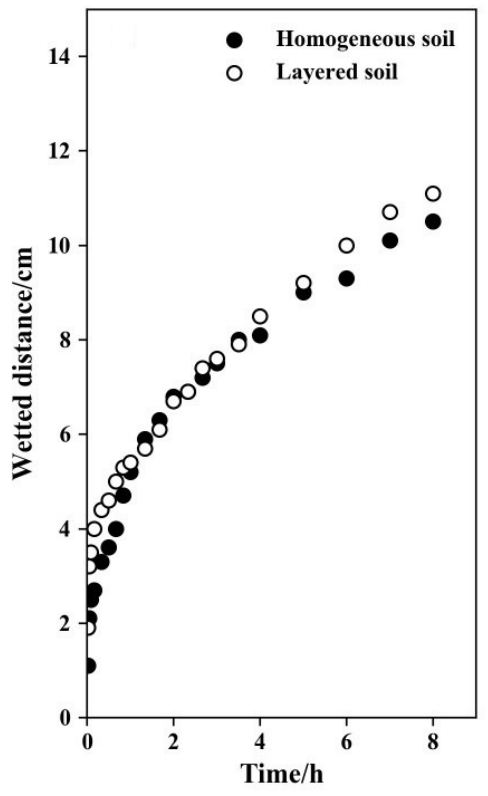

(b) Horizontal directions

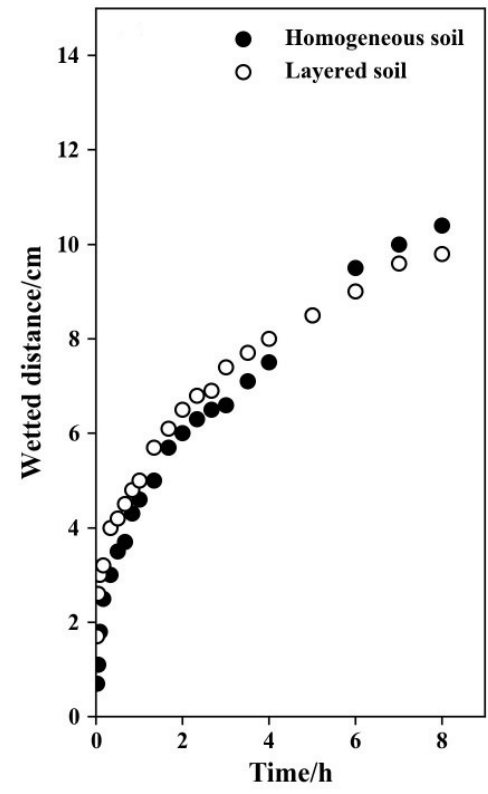

(c) Downward directions

Figure 7. Evolution of maximum wetting front movement distance.

\subsubsection{Effect of Layer Interface on Water Infiltration}

To explore the influence of the layer interface on water infiltration in vertical tube irrigation, movements of the wetting front above and below the layer interface were analyzed. Figure 8 presents the evolution of wetting front migration distance in layered soil, and Figure 9 presents the evolution of wetting front migration rate over time.

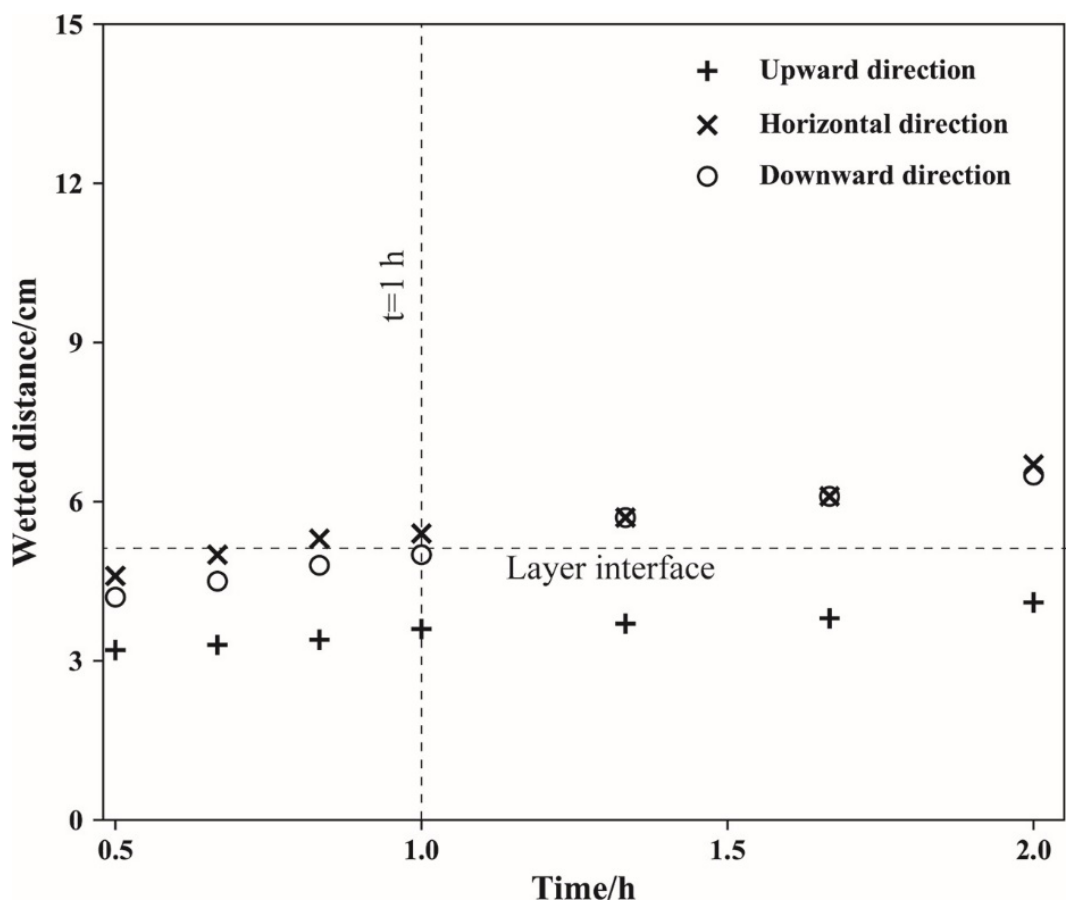

Figure 8. Evolution of wetting-front migration distance in layered soil. 


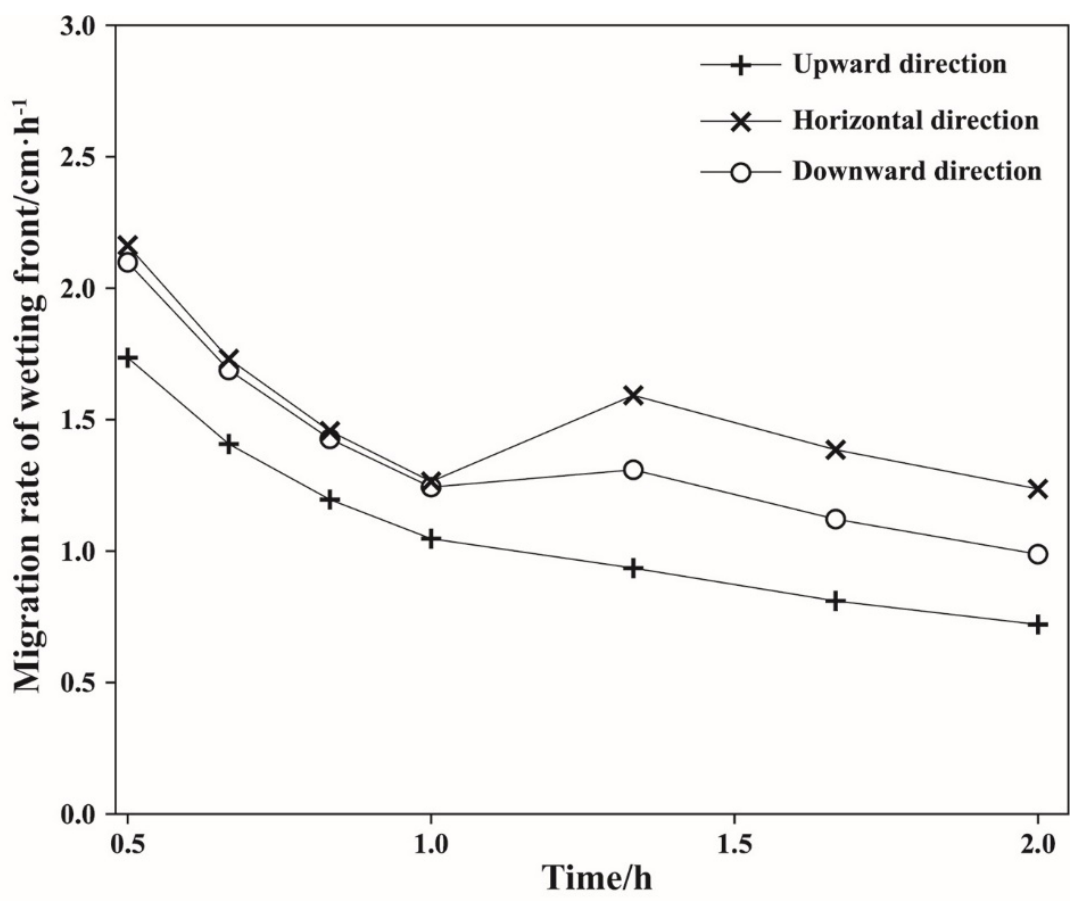

Figure 9. Migration of wetting front in layered soil.

In Figure 8, when the infiltration time was less than $1 \mathrm{~h}$, the upward wetting front migration distance was the smallest. The horizontal wetting front migration distance was slightly smaller than that of the downward wetting front, and the wetting front migration rate decreased. When the infiltration time was $1 \mathrm{~h}$, the downward wetting-front migration distance reached $5.0 \mathrm{~cm}$ (i.e., water migrated to the layer interface). The downward wetting-front movement was blocked, and the wetting-front movement rate reached the first trough (Figure 9).

As shown in Figure 9, when the infiltration time was greater than $1 \mathrm{~h}$, the downward and horizontal wetting front migration rates increased, and the horizontal wetting front migration rate increased faster than that of the downward wetting front. After $80 \mathrm{~min}$ of infiltration, the horizontal and vertical wet front movement rates began to decrease simultaneously. During the infiltration process, the vertical upward wetting-front movement rate gradually decreased over time.

Water transport in layered soil was affected by the layer interface. The wetting front arrives at the layer interface-the infiltration rate is believed to decrease at the wetting front arrival time to the interface of the two layers-because the attraction is reduced. Water infiltration in homogeneous soil was affected by soil and gravity during the infiltration stage before reaching the layer interface. After reaching and passing through the layer interface, water could not move downward and accumulated in the upper layer. This promoted horizontal water movement and increased horizontal wetting front speed.

Layered soil infiltration, three-dimensional vertical pipe irrigation, and water were considerably affected by the layer interface. The layer interface hinders downward migration of moisture but promotes water transport in other directions, particularly horizontally. Therefore, the wetting front rate fluctuated at the layer interface. In addition, the water migration rate was affected by the high hydraulic conductivity of sand. At larger permeabilities of the lower soil layer, the advancing speed of the wetting front increases [20].

\subsubsection{Variation in Soil Water Content}

Figure 10a,b illustrate variations in soil moisture content over time during homogeneous and layered soil infiltration. During homogeneous soil infiltration, soil moisture over time gradually increased. At the end of infiltration $(8 \mathrm{~h})$, the soil moisture content reached $32.6 \%$ at point $C$ and $27.8 \%$ 
at point $\mathrm{A}$. The moisture content at points $\mathrm{B}$ and $\mathrm{D}$ (particularly point $\mathrm{B}$ ) lagged because of the effect of gravity, which promoted the movement of water. In layered soil, moisture content at points A, $\mathrm{B}$, and $\mathrm{C}$ gradually increased over the first hour, whereas that above the silty loam layer interfaces increased relatively rapidly. After infiltration, the largest change was at point $C$, which reached $37.6 \%$ moisture content. Points A and B had $37.2 \%$ and $31.6 \%$, respectively. Point D in the sand below the layer interface reached $11.4 \%$ because the layer interface hindered moisture diffusion into the sand below. In this layered soil in which the upper layer is silty soil and the lower layer is sandy soil, the upper layer of the soil aided the retention for water, improving the moisture content above the layer interface. Suitable soil water content in root zones is beneficial for crop growth [1]. Vertical tube irrigation in layered soil can effectively reduce the amount of water infiltration and increase water content in the upper soil and maintain the soil water moisture within a constant range.

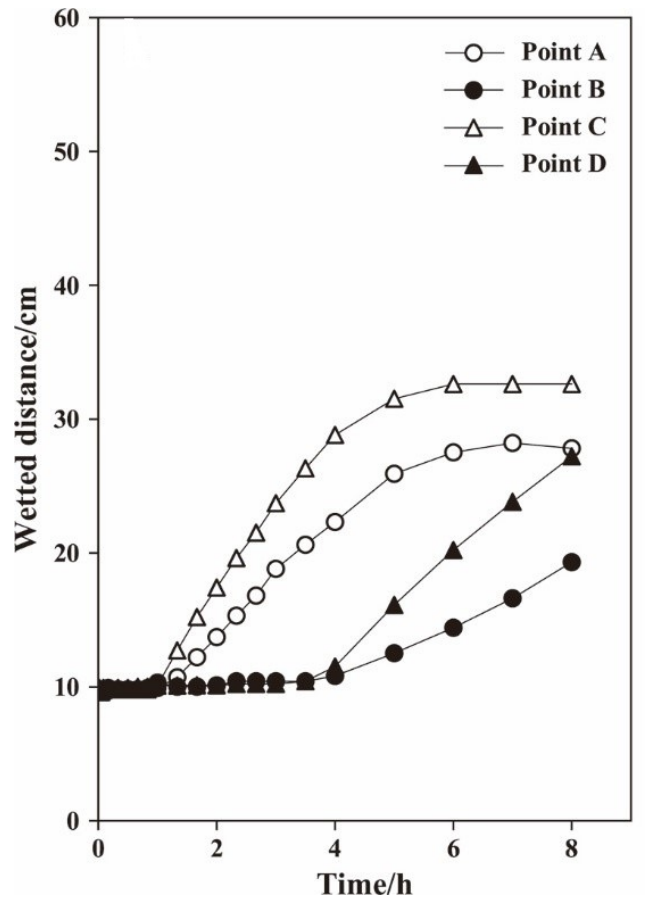

(a) Homogeneous soil

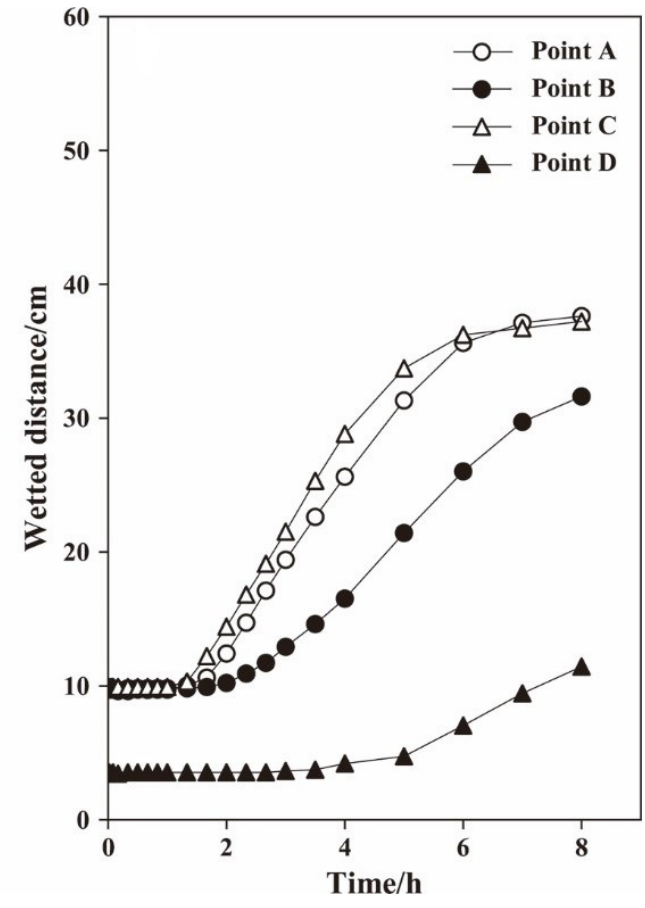

(b) Layered soil

Figure 10. Migration of soil moisture content over time monitored using soil sensors.

As presented in Figure 11, after infiltration $(8 \mathrm{~h})$, the soil moisture content reached a maximum (close to saturation) at the vertical tube irrigation outlet (depth $=20 \mathrm{~cm}$ ). The soil moisture contents of homogeneous and layered soil were $39.13 \%$ and $40.08 \%$, respectively. Ponding infiltration is one-dimensional, and after the upper soil is saturated, water begins to migrate vertically and exhibits a "finger flow" [33] phenomenon in the soil. However, in the process of vertical tube infiltration, the water content at the outlet was the highest, and the layer interface changes the shape of the wetted body instead of generating preferential flow, as is the case in one-dimensional vertical infiltration. 


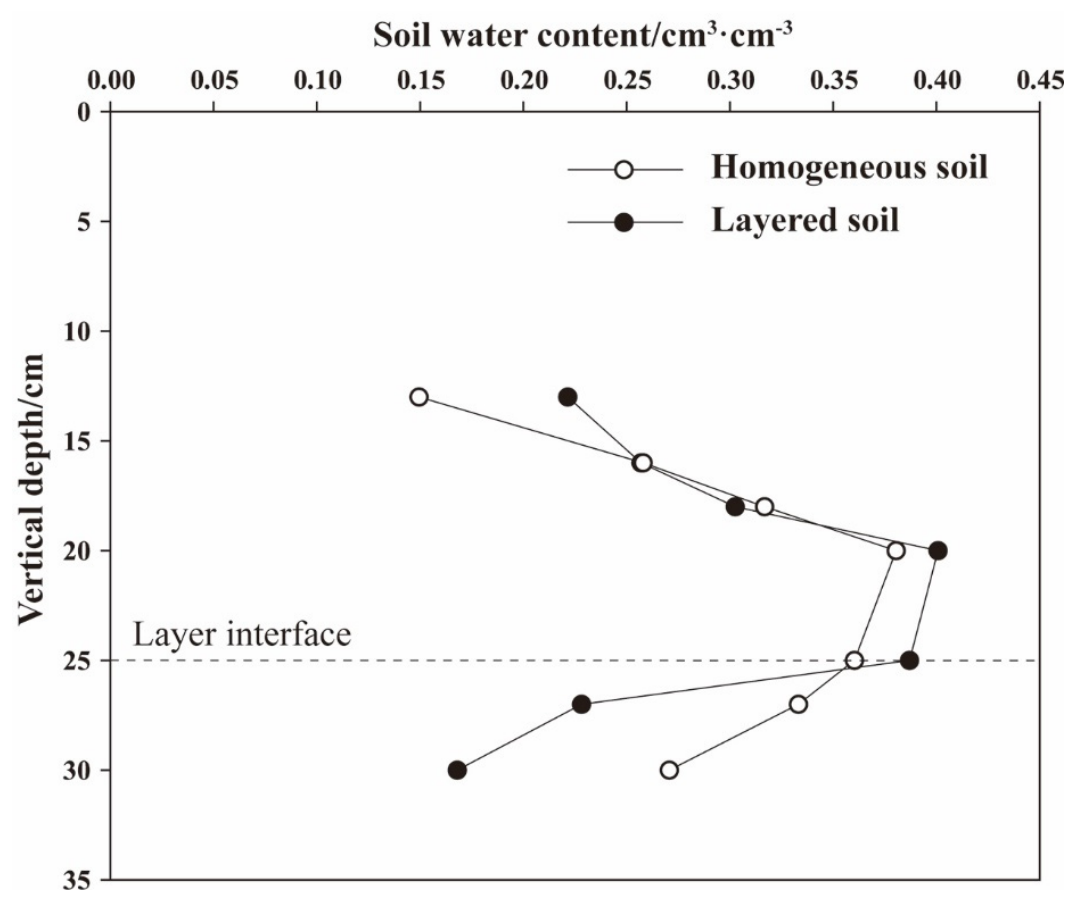

Figure 11. Soil moisture content by depth.

\section{Discussion}

\subsection{Effects of Vertical Tube Irrigation on Jujube Yield and IWP}

Irrigation amount and jujube yield were compared between surface drip and vertical tube irrigation. Vertical tube irrigation yielded obvious savings in water, at an irrigation amount of $207 \pm 41 \mathrm{~mm}$ compared with $489 \pm 5 \mathrm{~mm}$ for drip irrigation. After surface irrigation, the soil moisture content increased rapidly after irrigation and then gradually decreased because of the redistribution and evaporation of water in the soil [8]. Under high temperature, a large amount of soil moisture evaporates. Thus, in soils with a surface depth of $0-50 \mathrm{~cm}$, the soil water content of surface drip irrigation gradually increased, but only to $12-20 \%$. Vertical tube irrigation is a type of subsurface irrigation. The burial depth of the vertical tube water outlet was $40 \mathrm{~cm}$, and the surface evaporation was small. Therefore, soil water content within $10-40 \mathrm{~cm}$ was maintained between $26 \%$ and $35 \%$ in the jujube field experiment with vertical tube irrigation.

Furthermore, the soil profile exhibited an obvious stratified structure, and the hydraulic conductivity was lower in the upper layer than in the lower layer. For surface drip irrigation technology, water gradually moved downward from the surface, and when water passes through the layer interface, it soon enters the sandy loam and spreads. Rawls et al. [34] found that sandy soil has high hydraulic conductivity and much less holding capacity under conditions of high soil water content. The maximum water content for surface drip irrigation was observed 50-80 $\mathrm{cm}$ below the surface. The soil from 50-200 cm was sandy loam, and the water was easily transported downward. However, because the main roots of jujube are distributed in the $0-50 \mathrm{~cm}$ soil layer below the surface, the plant has difficulty absorbing water in this part of the soil, resulting in low IWP of surface drip irrigation. Similar to porous ceramic irrigation [10], we noted a feedback regulation effect between the discharge of vertical tube irrigation and soil water content. When the soil water content was high, the discharge of vertical tube irrigation decreased; furthermore, because the soil profile exhibited an obvious stratified structure, the layer interface reduced the downward migration of water, and kept the water in the main root layer area. The IWP of vertical tube irrigation was 1.6 times higher than that of surface drip irrigation. The results demonstrated that this limited water supply could reduce jujube 
water consumption and that a greater abundance of soil water can support jujube growth, as also shown by Ma et al. [35].

\subsection{Infiltration Characteristics in Layered Soil with Vertical Tube in Laboratory}

In a laboratory, the infiltration law of vertical tube irrigation in layered soil and the spatiotemporal distributions of soil moisture were analyzed. The moisture content of wetted layered soil below the layer interface was less than that of homogenous soil in the same position. Yang et al. [36] demonstrated that the finer layer with low saturated permeability limited the flux into the coarser layer. The moisture in layered soil passed through the layer interface and was affected by the difference in soil water potential, which caused water to accumulate in the upper soil and gradually increase the soil water content. When the influent suction in the sandy soil was greater than the soil water potential in the upper soil, under the action of gravity potential, the water began to move downward, which reduced the infiltration amount and the irrigation amount.

In contrast to that of underground drip irrigation, the discharge of vertical tube irrigation was mainly affected by soil water potential. Reducing the irrigation amount can effectively maintain soil moisture in the main root zones. Improving the soil water content in the main root zones can increase root-to-water use efficiency [37]. However, the burial depth of the water outlet of the vertical tube emitter must be determined according to the observed soil profile structure, in doing so, users can fully leverage the advantages of this irrigation technology.

\section{Conclusions}

This study performed field and laboratory experiments on vertical tube irrigation. When jujube trees were subject to vertical tube irrigation and surface drip irrigation, vertical tube irrigation had the (slightly) lower jujube yield but better (i.e., smaller) irrigation amount, at approximately $42.3 \%$ of the irrigation amount of surface drip irrigation. The IWP of vertical tube irrigation was 1.6 times that of surface drip irrigation. The water content for vertical tube irrigation was mainly concentrated in the root distribution area of the soil (0-50 cm deep), which improved the root system's water utilization rate. Vertical tube irrigation makes good use of the water barrier effect of the layer interface. The layer interface in vertical tube irrigation prevented some downward movement of water. Moisture was effectively prevented from spreading to the sand, and the moisture content of the upper soil increased. It promoted the horizontal diffusion of the wetting front, making the soil moisture content of the main root layer relatively constant and reducing evaporation and deep leakage from the surface.

Vertical tube irrigation is a continuous irrigation method with a small amount of irrigation, but it can maintain a suitable soil moisture content in the root layer of the crop and create a favorable water environment for crop growth. The application of vertical tube irrigation technology in jujube cultivation can economize the use of irrigation water, which can greatly aid jujube cultivation in arid Xinjiang. We conducted laboratory analyses of the water-saving principle underlying vertical tube irrigation under layered soil conditions. These results aid the study of the hydraulic characteristics and soil water distributions that are associated with irrigation systems of the subsurface-drip and porous-ceramic types. However, this paper only discusses a layered method. We intend to analyze various combinations of layered soil and the infiltration characteristics of vertical tube irrigation technology in different soil structures to provide a theoretical basis for the practical application of vertical tube irrigation.

Author Contributions: Data curation, C.W., Z.D. and Z.P.; writing—original draft preparation, C.W.; writing—review and editing, C.W., D.B., X.W. and Y.L.; funding acquisition and supervision, D.B. All authors have read and agreed to the published version of the manuscript.

Funding: This work was supported by the Projects of the National Natural Science Foundation of China, grant numbers 41571222,51909208.

Conflicts of Interest: The authors declare no conflict of interest. 


\section{References}

1. Patel, N.; Rajput, T.B.S. Effect of drip tape placement depth and irrigation level on yield of potato. Agric. Water Manag. 2007, 88, 209-223. [CrossRef]

2. Patel, N.; Rajput, T.B.S. Dynamics and modeling of soil water under subsurface drip irrigated onion. Agric. Water Manag. 2008, 95, 1335-1349. [CrossRef]

3. Abuarab, M.; Mostafa, E.; Ibrahim, M. Effect of air injection under subsurface drip irrigation on yield and water use efficiency of corn in a sandy clay loam soil. J. Adv. Res. 2013, 4, 493-499. [CrossRef] [PubMed]

4. Mo, Y.; Li, G.; Wang, D. A sowing method for subsurface drip irrigation that increases the emergence rate, yield, and water use efficiency in spring corn. Agric. Water Manag. 2017, 179, 288-295. [CrossRef]

5. Coltro, L.; Marton, L.F.M.; Pilecco, F.P.; Pilecco, A.C.; Mattei, L.F. Environmental profile of rice production in Southern Brazil: A comparison between irrigated and subsurface drip irrigated cropping systems. J. Clean. Prod. 2017, 153, 491-505. [CrossRef]

6. Pendergast, L.; Bhattarai, S.P.; Midmore, D.J. Evaluation of aerated subsurface drip irrigation on yield, dry weight partitioning and water use efficiency of a broad-acre chickpea (Cicer arietinum, L.) in a vertosol. Agric. Water Manag. 2019, 217, 38-46. [CrossRef]

7. Li, J.S.; Li, Y.F.; Zhang, H. Tomato Yield and Quality and Emitter Clogging as Affected by Chlorination Schemes of Drip Irrigation Systems Applying Sewage Effluent. J. Integr. Agric. 2012, 11, 1744-1754. [CrossRef]

8. Martínez, J.; Reca, J. Water use efficiency of surface drip irrigation versus an alternative subsurface drip irrigation method. J. Irrig. Drain. Eng. 2014, 140, 1-9. [CrossRef]

9. Jacques, D.; Fox, G.; White, P. Farm level economic analysis of subsurface drip irrigation in Ontario corn production. Agric. Water Manag. 2018, 203, 333-343. [CrossRef]

10. Cai, Y.; Wu, P.; Zhang, L.; Zhu, D.; Chen, J.; Wu, S.J.; Zhao, X. Simulation of soil water movement under subsurface irrigation with porous ceramic emitter. Agric. Water Manag. 2017, 192, 244-256. [CrossRef]

11. Zhu, J.; Jin, J.; Yang, C. Effects of trace quantity irrigation on yield, dry matter portioning and water use efficiency of spherical fennel grown in greenhouse. Paiguan Jixie Gongcheng Xuebao/J. Drain. Irrig. Mach. Eng. 2014, 32, 338-342.

12. Song, P.; Li, Y.; Zhou, B.; Zhou, C.; Zhang, Z.; Li, J. Controlling mechanism of chlorination on emitter bio-clogging for drip irrigation using reclaimed water. Agric. Water Manag. 2017, 184, 36-45. [CrossRef]

13. Zhou, H.; Li, Y.; Wang, Y.; Zhou, B.; Bhattarai, R. Composite fouling of drip emitters applying surface water with high sand concentration: Dynamic variation and formation mechanism. Agric. Water Manag. 2019, 215, 25-43. [CrossRef]

14. Das Gupta, A.; Babel, M.S.; Ashrafi, S. Effect of soil texture on the emission characteristics of porous clay pipe for subsurface irrigation. Irrig. Sci. 2009, 27, 201-208. [CrossRef]

15. Kandelous, M.M.; Šimůnek, J. Comparison of numerical, analytical, and empirical models to estimate wetting patterns for surface and subsurface drip irrigation. Irrig. Sci. 2010, 28, 435-444. [CrossRef]

16. Yao, W.W.; Ma, X.Y.; Li, J.; Parkes, M. Simulation of point source wetting pattern of subsurface drip irrigation. Irrig. Sci. 2011, 29, 331-339. [CrossRef]

17. Ren, C.; Zhao, Y.; Wang, J.; Bai, D.; Zhao, X.; Tian, J. Lateral hydraulic performance of subsurface drip irrigation based on spatial variability of soil: Simulation. Agric. Water Manag. 2017, 193, 232-239. [CrossRef]

18. Bai, D.; He, J.; Guo, L.; Wang, L. Infiltration characteristics of vertical tube subirrigation as affected by various factors. Trans. Chin. Soc. Agric. Eng. 2016, 32, 101-105.

19. Bai, D.; Sun, S.; Ren, P.; Xu, X. Temporal and spatial variation of wetting volume under sub-irrigation with vertical emitter. Trans. Chin. Soc. Agric. Eng. 2018, 34, 107-113.

20. Mohammadzadeh-Habili, J.; Heidarpour, M. Application of the Green-Ampt model for infiltration into layered soils. J. Hydrol. 2015, 527, 824-832. [CrossRef]

21. Soulis, K.X.; Elmaloglou, S. Optimum soil water content sensors placement for surface drip irrigation scheduling in layered soils. Comput. Electron. Agric. 2018, 152, 1-8. [CrossRef]

22. Cho, K.W.; Song, K.G.; Cho, J.W.; Kim, T.G.; Ahn, K.H. Removal of nitrogen by a layered soil infiltration system during intermittent storm events. Chemosphere 2009, 76, 690-696. [CrossRef] [PubMed]

23. Cui, G.; Zhu, J. Prediction of unsaturated flow and water backfill during infiltration in layered soils. J. Hydrol. 2018, 557, 509-521. [CrossRef] 
24. Ma, Y.; Feng, S.; Su, D.; Gao, G.; Huo, Z. Modeling water infiltration in a large layered soil column with a modified Green-Ampt model and HYDRUS-1D. Comput. Electron. Agric. 2010, 71, 40-47. [CrossRef]

25. Deng, P.; Zhu, J. Analysis of effective Green-Ampt hydraulic parameters for vertically layered soils. J. Hydrol. 2016, 538, 705-712. [CrossRef]

26. Li, J.S.; Ji, H.Y.; Bei, L.I.; Liu, Y.C. Wetting Patterns and Nitrate Distributions in Layered-Textural Soils Under Drip Irrigation. Agric. Sci. China 2007, 6, 970-980. [CrossRef]

27. van Genuchten, M.T. A closed form equation for predicting the hydraulic conductivityof unsaturated soils. Soil Sci. Soc. Am. J. 1980, 44, 892-898. [CrossRef]

28. van Genuchten, M.; Leij, F.J.; Yates, S.R. The RETC Code for Quantifying the Hydraulic Functions Unsaturated Soils; EPA/600/2-91/065; R.S. Kerr Environmental Research Laboratory, U.S. Environmental Protection Agency: Okla, LA, USA, 1991.

29. Monaco, F.; Sali, G. How water amounts and management options drive Irrigation Water Productivity of rice. A multivariate analysis based on field experiment data. Agric. Water Manag. 2018, 195, 47-57. [CrossRef]

30. Dai, Z.; Fei, L.; Huang, D.; Zeng, J.; Chen, L.; Cai, Y. Coupling effects of irrigation and nitrogen levels on yield, water and nitrogen use efficiency of surge-root irrigated jujube in a semiarid region. Agric. Water Manag. 2019, 213, 146-154. [CrossRef]

31. Li, Y.; Ren, X.; Hill, R.; Malone, R.; Zhao, Y. Characteristics of Water Infiltration in Layered Water-Repellent Soils. Pedosphere 2018, 28, 775-792. [CrossRef]

32. Huang, M.; Barbour, S.L.; Elshorbagy, A.; Zettl, J.; Si, B.C. Effects of Variably Layered Coarse Textured Soils on Plant Available Water and Forest Productivity. Procedia Environ. Sci. 2013, 19, 148-157. [CrossRef]

33. Allaire, S.E.; Dadfar, H.; Denault, J.T.; van Bochove, E.; Charles, A.; Thériault, G. Development of a method for estimating the likelihood of finger flow and lateral flow in canadian agricultural landscapes. J. Hydrol. 2011, 403, 261-277. [CrossRef]

34. Rawls, W.J.; Gish, T.J.; Brakensiek, D.L. Estimating soil water retention from soil physical properties and characteristics. Adv. Soil Sci. 1991, 16, 213234.

35. Ma, L.; Wang, X.; Gao, Z.; Wang, Y.; Nie, Z.; Liu, X. Canopy pruning as a strategy for saving water in a dry land jujube plantation in a loess hilly region of China. Agric. Water Manag. 2019, 216, 436-443. [CrossRef]

36. Yang, H.; Rahardjo, H.; Leong, E.C. Behavior of unsaturated layered soil columns during infiltration. J. Hydrol. Eng. 2006, 11, 329-337. [CrossRef]

37. Wang, J.; Niu, W.; Li, Y.; Lv, W. Subsurface drip irrigation enhances soil nitrogen and phosphorus metabolism in tomato root zones and promotes tomato growth. Appl. Soil Ecol. 2018, 124, 240-251. [CrossRef] 